\title{
DESENVOLVIMENTO RURAL SUSTENTÁVEL NO BRASIL: PERSPECTIVAS A PARTIR DA INTEGRAÇÃO DE AÇÕES PÚBLICAS E PRIVADAS COM BASE NA AGROECOLOGIA*
}

\author{
Renato Linhares de Assis ${ }^{\S}$
}

\begin{abstract}
RESUMO
O objetivo deste trabalho é apresentar uma opção para o estabelecimento de um processo de desenvolvimento rural sustentável com base na agroecologia. Para isto, inicialmente é feita uma análise do processo de difusão, no Brasil, de sistemas de produção agroecológicos. Posteriormente, discutem-se o conceito de desenvolvimento sustentável e as possibilidades de sua implementação diante das dificuldades que se apresentam com a globalização da economia. Em seqüência são apresentadas questões relacionadas às demandas de políticas públicas para a implementação de um processo de desenvolvimento rural sustentável, com base na ação local, que tenha por mote sistemas de produção agroecológicos. Apresentam-se, então, algumas premissas e recomendações gerais para a implementação desse processo. Conclui-se que o encaminhamento proposto somente será possível com uma ação duradoura e integrada dos diferentes níveis de ação do poder público, associada ao envolvimento efetivo da sociedade na construção de soluções.
\end{abstract}

Palavras-chave: agricultura familiar, agricultura orgânica, políticas públicas.

\begin{abstract}
This article aims to present an option for establishment of agroecological based sustainable rural development. Initially, an analysis is made of the process of diffusion of agroecological production systems in Brazil. Afterwards, the concept of sustainable development and possibilities of its accomplishment in relation to the difficulties brought by global economy is discussed. Following this, some questions are presented about public policy demands for the accomplishment of sustainable rural development, based at local action and related to agroecological production systems. Some premises and general recommendations are also presented for the accomplishment of this process. It is concluded that the execution of the proposal ideas only will be possible with enduring and integrated action of the different levels of action by public authorities, associated with real involvement of the society in the building of solutions.
\end{abstract}

Key words: family agriculture, organic agriculture, public policies.

JEL classification: Q16.

Parte da tese de doutorado do autor em Economia Aplicada - área de concentração em Desenvolvimento Econômico, Espaço e Meio Ambiente (Universidade Estadual de Campinas).

$\S$ Engenheiro Agrônomo (PhD), Pesquisador da Empresa Brasileira de Pesquisa Agropecuária/Centro Nacional de Pesquisa de Agrobiologia (Embrapa Agrobiologia); caixa postal 74505, CEP 23850-970, Seropédica - RJ. renato@cnpab.embrapa.br

Recebido em abril de 2004. Aceito em junho de 2005. 


\section{INTRODUÇÃO}

Analisando-se historicamente o processo de evolução tecnológica na agricultura, verifica-se que esta sempre foi objeto das observações atentas de todos os que procuravam melhorar as práticas correntes. Isto implicou um acúmulo de conhecimentos que possibilitasse, ao ser humano, dispor de tecnologias de produção agrícola que diminuíssem as restrições ambientais a esta atividade. Assim, por meio do artificialismo do ambiente natural, procurou-se sempre obter alimentos em qualidade e quantidade suficiente para garantir os padrões nutricionais e a sustentabilidade das diferentes sociedades.

Até a Segunda Revolução Agrícola (séculos XVIII e XIX), ${ }^{1}$ com a disseminação do sistema de rotação que ficou conhecido como "Norfolk", 2 o processo de inovação na agricultura caracterizou-se por tecnologias, como rotação de culturas e integração entre atividades de produção vegetal e animal, que respeitavam o ambiente ao procurarem superar as limitações ecológicas para a atividade agrícola, a partir da utilização inteligente das próprias leis da natureza. Entretanto, com a disseminação dos conhecimentos da química agrícola, a partir do século XIX, este processo teve sua lógica modificada, passando-se, de maneira geral, a considerar não ser necessário seguir as regras ecológicas.

As regras ecológicas básicas de gestão da natureza passaram a ser vistas como desnecessárias à prática agrícola por se considerar que o caráter ambientalmente agressivo da então chamada agricultura moderna era um mal necessário, que podia ser moderado com algumas práticas conservacionistas. (Romeiro, 1996).

Nos marcos dessa concepção modernizadora na agricultura, a pesquisa e o desenvolvimento dos sistemas de produção foram orientados para a incorporação de pacotes tecnológicos tidos como de aplicação universal destinados a maximizar o rendimento dos cultivos em situações ecológicas profundamente distintas.

Com a crítica às implicações sociais da difusão dessa estratégia, cresceu, no Brasil e no resto do mundo subdesenvolvido, a preocupação com o que seria tecnologicamente apropriado para a pequena produção familiar. Embora o cerne tecnológico da "Revolução Verde" (variedades selecionadas, agroquímicos e irrigação) fosse neutro do ponto de vista da escala técnica, os relativamente elevados investimentos necessários para a adoção do pacote tecnológico levaram a uma disputa por recursos escassos nos países pobres, disputa ganha, obviamente, pelas elites agrícolas desses países. A exclusão dos agricultores pobres pela "barreira à entrada", representada pelos investimentos mínimos necessários, levou a uma mudança de atitude nas agências internacionais de pesquisa agropecuária.

Embora o "pacote tecnológico" da "Revolução Verde" continuasse sendo considerado, pela maioria dos pesquisadores e responsáveis pela pesquisa dessas instituições, como a opção tecnológica mais eficiente, ficou claro que para a grande maioria dos agricultores pobres a adoção dessas tecnologias não seria possível pelas razões apontadas acima, pelo menos a curto e médio prazos. Neste sentido, pensou-se ser indispensável oferecer alternativas, apropriadas (ou “intermediárias”), para a melhoria dos sistemas produtivos que fossem financeiramente acessíveis a esses produtores e lhes permitissem iniciar uma trajetória de capitalização para, no futuro, adotarem o pacote mais eficiente.

1 A Primeira Revolução Agrícola caracterizou-se pela disseminação do sistema de rotação trienal ocorrida entre os séculos XI e XIII, no entanto alguns mencionam apenas este segundo momento como Revolução Ágrícola. Para mais detalhes, ver Boserup (1987); Romeiro (1998); e Veiga (1991).

2 Condado britânico a partir do qual este sistema se originou. 
Assim, em vez de adaptar o ecossistema agrícola às variedades de alta capacidade produtiva, por meio de investimentos elevados em agroquímicos e irrigação, passou-se a pesquisar alternativas de adaptação das variedades às restrições de cada ecossistema agrícola: variedades resistentes a seca, a doenças, a baixa fertilidade e/ou toxidez dos solos, fixação de nitrogênio atmosférico etc. Este redirecionamento, porém, não rompeu com a fundamentação básica da "Revolução Verde", de busca de simplificação do ambiente agrícola como forma de maximizar a produtividade.

Com outro direcionamento, surgiram, no Brasil e no mundo, movimentos de agricultura alternativos ao convencional, contrapondo-se ao uso abusivo de insumos agrícolas industrializados, da dissipação do conhecimento tradicional e da deterioração da base social de produção de alimentos. Para esses movimentos a solução não estava em alternativas parciais, mas no rompimento com a monocultura e o redesenho dos sistemas de produção de forma a minimizar a necessidade de insumos externos à propriedade. Intensificou-se, então, o reconhecimento de modelos agrícolas que considerassem a importância das diferentes interações ecológicas para a produção agrícola.

A partir desses movimentos surgiram correntes de atuação com diversas denominações para diferentes sistemas de produção (Assis, 1993; Costa, 1987; Jesus, 1985 e 1996) empregados em diferentes condições ambientais, apresentando resultados satisfatórios do ponto de vista ecológico, agronômico, econômico e social. (Almeida, 1998; Assis, 1993; Carmo et al., 1988; Carmo e Magalhães, 1999; Darolt, 1999 e 2000; Nascimento Jr., 1995; Ndiaye et al., 1999).

A agroecologia é uma ciência surgida na década de $1970{ }^{3}$ como forma de estabelecer uma base teórica para esses diferentes movimentos de agricultura não convencional. ${ }^{4}$ É uma ciência que busca o entendimento do funcionamento de agroecossistemas ${ }^{5}$ complexos, bem como das diferentes interações presentes nestes, tendo como princípio a conservação e a ampliação da biodiversidade dos sistemas agrícolas como base para produzir auto-regulação e, conseqüentemente, sustentabilidade.

A agroecologia propõe alternativas para minimizar a artificialização do ambiente natural pela agricultura, para o que apresenta uma série de princípios e metodologias para estudar, analisar, dirigir, desenhar e avaliar agroecossistemas. Utiliza-se de um enfoque científico, que tem suas próprias ferramentas, teorias e hipóteses, o que lhe permite trabalhar no âmbito dos agroecossistemas e no desenvolvimento de sistemas agrícolas complexos e diversificados.

$\mathrm{Na}$ natureza, a estabilidade está intimamente ligada à diversidade, sendo a agricultura uma atividade que, por definição, rompe com este equilíbrio ao estabelecer uma simplificação do ecossistema original. A conseqüência maior dessa simplificação, conforme afirma Romeiro (1996), é a perda da capacidade de auto-regulação natural, fazendo com que o equilíbrio e a estabilidade da agricultura, enquanto sistema simplificado pelo homem, passem a depender de uma permanente interferência deste último.

Além disso, na busca de auto-regulação dos agroecossistemas como forma de atingir a sustentabilidade, a agroecologia não só enfatiza a importância dos parâmetros agronômicos e ecológicos, como também das questões socioeconômicas, resgatando o fato de que a agricultura, além de ser um processo ecológico, é um processo social, ou seja, o desenvolvimento tecnológico deve estar inserido num processo amplo em que a tecnologia seja instrumento para um desenvolvimento rural que atenda às demandas sociais e econômicas.

3 “O uso contemporâneo do termo agroecologia data dos anos 70, mas a ciência e a prática da agroecologia tem a idade da própria agricultura."(Hecht, 1989, p. 25).

4 "O maior contribuinte intelectual à agroecologia foi o movimento em prol do meio ambiente nas décadas de 60 e 70 . Assim como o ambientalismo foi absorvido pela agroecologia, algumas partes do discurso agroecológico com posiçóes críticas sobre produção orientada passou à agronomia, aumentando a sensibilidade às altas taxas de exportação de recursos." (Hecht, 1989, p. 33).

5 "Um agroecossistema é um local de produção agrícola - uma propriedade agrícola por exemplo - compreendido como um ecossistema. O conceito de agroecossistema proporciona uma estrutura com a qual podemos analisar os sistemas de produção de alimentos como um todo, incluindo seus conjuntos complexos de insumos e produção e as interconexões que os compõem." (Gliessman, 2000, p. 61). 
Nesse sentido, e na medida em que o objetivo desse trabalho é discutir propostas de ações públicas e privadas que favoreçam a implementação de um processo de desenvolvimento rural sustentável, a agroecologia caracteriza-se como opção para a fundamentação teórica desse processo, que se entende, aqui, como de uma co-evolução dos sistemas naturais e sociais.

Para isso, o texto estrutura-se em cinco tópicos, além desta introdução. O tópico 2 analisa o processo de difusão da agroecologia no Brasil vis-à-vis à estrutura social de organização da produção. O terceiro tópico estabelece o entendimento do que é apresentado como desenvolvimento sustentável para, em seguida, discutir a viabilidade de sua consecução ante a dinâmica social que a globalização determina.

No quarto tópico é feita uma abordagem relativa à implementação de políticas em que o mote seja a difusão de sistemas de produção agroecológicos. Trabalha-se, neste caso, com instrumentos de política agrícola e ambiental, como forma complementar de uma ação do setor público, que antes de tudo deve ser educativa e integrada com as comunidades locais.

Em seguida, no quinto tópico, propõe-se uma ação de pensar e agir localmente, como forma de implementar um processo de desenvolvimento rural sustentável com base na agroecologia. $\mathrm{O}$ último tópico conclui afirmando que no Brasil este processo deverá ocorrer por meio de um projeto político coordenado com as diferentes regiões do País, que assegure a participação democrática das populações locais em suas diferentes expressões.

\section{A DifuSÃo DE SISTEMAS AGROECOLÓGICOS DE PRODUÇÃo NO BRASIL}

Analisando-se os princípios teóricos da agroecologia diante das características da produção familiar, verifica-se que a agroecologia se adequa mais facilmente à realidade de sistemas de organização familiar da produção agrícola, na medida em que estes possuem estruturas de produção diversificadas e com um nível de complexidade desejado, sem prejuízo das atividades de supervisão e controle do processo de trabalho.

Em oposição, para grandes produtores patronais, apesar de não se considerar que a agricultura orgânica com base agroecológica seja inviável, verifica-se que nestes casos as dificuldades são maiores, especialmente no que se refere à regra de diversificação do agroecossistema. Trabalha-se, no caso, próximo ao limite inferior da complexidade desejada, de forma a manter-se dentro das premissas agroecológicas e assim assegurar sua sustentabilidade.

Outra questão refere-se ao fato de que os agricultores patronais têm como característica uma forte interação com o mercado, fato este que se reflete no processo de adoção de tecnologias que visam sempre aos ganhos imediatos de produtividade, independentemente do modo de produção. Assim, esta produção patronal se caracteriza, antes da mudança para agricultura orgânica, pela adoção intensiva do pacote da "Revolução Verde", dificultando, para estes agricultores, a mudança para sistemas orgânicos de produção devido a perdas iniciais de produtividade que representam importante componente do custo deste processo de conversão

Além disto, para a produção orgânica patronal, tal como ocorre com a agricultura convencional, a maior interação com o mercado estabelece, sobre estes agricultores, forte pressão de demanda por certos produtos orgânicos, em razão da maior facilidade de acesso a informações e a mercados diferenciados, que muitas vezes leva à busca de resultados imediatos de produtividade que põem em risco a sustentabilidade da atividade agrícola.

De acordo com Assis (2002), verifica-se que o custo de conversão, para a agricultura orgânica com bases agroecológicas, é maior para agricultores com padrão inicial de produtividade mais 
elevado. No entanto, no que se refere à recuperação da produtividade, agricultores patronais apresentam maiores possibilidades, pois verifica-se que esta é função do tempo necessário para o aprendizado do manejo orgânico e da capacidade de investimento do agricultor para recondicionamento do solo/planta ao novo sistema de produção, condições presentes, de forma mais favorável, neste estrato socioeconômico de agricultores que possuem maiores facilidades de acesso à informação e padrão de capitalização.

Porém, no caso da produção familiar, esta redução inicial de produtividade tem seu peso reduzido, posto que para este modo de produção a adoção de tecnologias da "Revolução Verde" se deu, em geral, de forma bem menos intensiva, ou mesmo não ocorreu, principalmente no caso de produtores simples de mercadorias ou semi-assalariados com frágil inserção no mercado ou produtores de subsistência. Nesses casos, ao contrário do que se observa com a produção empresarial, a adoção de tecnologias agroecológicas intensivas em mão-de-obra, mas pouco intensivas em capital, pode determinar ganhos de produtividade e redução do risco econômico da atividade agrícola.

A organização social da produção também é importante quando se analisa outro componente do custo de conversão para a agricultura orgânica com bases agroecológicas. Trata-se do acréscimo na demanda por trabalho que se observa quando da adoção deste sistema de produção. Neste caso, onde a produção agrícola é baseada na mão-de-obra familiar, este custo não é em geral percebido em virtude de não representar desembolso financeiro, diferentemente da produção empresarial em que este componente de custo tem grande peso na conversão.

Entende-se, assim, que custos e barreiras à entrada, presentes no processo de transição para modelos agroecológicos de produção, dificultam uma resposta mais efetiva da maioria dos agricultores, mesmo considerando o nível de preços que os consumidores de produtos agroecológicos estão atualmente dispostos a pagar.

Deve-se ressaltar que a diferenciação de preços, a maior observada no mercado de produtos orgânicos, apesar de representar importante estímulo à adoção da agricultura orgânica por parte de novos agricultores, não deve ser entendida como a percepção de uma necessidade de que os preços praticados neste mercado remunerem eventuais custos de produção superiores observados na produção orgânica. ${ }^{6}$

O que se verifica é que o sobrepreço em questão se deve, na verdade, a questões de oferta e procura presentes em um mercado diferenciado, composto por consumidores com limites em sua disposição a pagar, estabelecidos a partir do atendimento a exigências de padrões de consumo, que não se restringem à produção orgânica em si, referindo-se também a questões relacionadas a tamanho, cheiro e aparência em geral, ou seja, trata-se de um mercado especializado, e que, em razão do atual padrão de profissionalismo praticado, apresenta restrições à entrada de agricultores que não apresentem uma organização mínima.

Este fato refere-se principalmente à agricultura familiar, que segue padrões de racionalidade que fogem à lógica de mercado de máxima eficiência econômica, e trilham o caminho do ótimo e satisfatório possível, onde a organização desejada não visa atender aos padrões estabelecidos pelas demandas de mercado, mas, sim, às necessidades de satisfação e desejo subjetivadas na lógica da produção familiar.

6 Ndiaye et al. (1999), comparando a produção de quatro hortaliças em sistemas orgânico e convencional, observaram que para aipim, batata-doce e couve o custo variável total na agricultura convencional foi maior $(58,1 \%, 71,9 \%$ e $13,4 \%$, respectivamente) e ligeiramente desfavorável à agricultura orgânica para o cultivo da alface $(3,1 \%)$. Analisando ainda o impacto do manejo orgânico sobre o resultado econômico, estes mesmos autores verificaram que a agricultura orgânica pode, em muitos casos, ser economicamente mais interessante, não só devido ao menor uso de insumos industrializados, como também a melhores resultados de produtividade, demonstrando que entre sete hortaliças produzidas organicamente quatro apresentaram produtividade superior ao padrão convencional. 
Desta forma, observa-se que os custos e barreiras à entrada se apresentam de forma diferenciada de acordo com o estrato socioeconômico do agricultor envolvido, especialmente no que se refere a produtores familiares e empresariais.

Em relação à agricultura familiar, destacam-se os produtores simples de mercadoria e semiassalariados, conforme descritos por Payés (1993), para os quais se verifica que modelos agroecológicos de produção podem ser a opção de desenvolvimento, na medida em que estes, em razão do custo, não utilizam o pacote agroquímico.

Nesse caso, a baixa capacidade de investimento não representa uma barreira à entrada, pois a readequação tecnológica ocorre via introdução de práticas que requerem basicamente a reorientação do trabalho. Porém, no que diz respeito à maior dificuldade de acesso a informações, percebese a necessidade de atuação estatal como facilitador neste processo.

Destarte, para superar as dificuldades anotadas para uma difusão ampliada no Brasil, de sistemas agroecológicos de produção, nas diferentes formas de organização social da produção, cabe ao Estado, no Brasil historicamente à margem do processo de difusão deste modo de produção, um papel fundamental, estabelecendo políticas públicas específicas, nas diferentes hierarquias de poder (federal, estadual e municipal), em suas competências específicas, particularmente nas áreas de crédito, pesquisa e extensão e, em especial, procurando abrir mercados, fomentar a produção e apoiar a organização autônoma de agricultores familiares, público este que apresenta maior potencial de inserção em um processo de desenvolvimento rural sustentável que tenha como mote tecnológico práticas agroecológicas.

Isso, porém, é ao mesmo tempo um grande desafio, na medida em que esbarra num quadro atual de crise financeira e fiscal de caráter global e na ideologia liberal dominante que estabelece o setor público como grande vilão dessa crise.

\section{O CONCEITO DE DESENVOLVIMENTO SUSTENTÁVEL E SUAS POSSIBILIDADES DE IM- PLEMENTAÇÃO}

Os enfoques tradicionais desenvolvimentistas consideram que se pode elevar indefinidamente o nível de riqueza material, ${ }^{7}$ sendo o crescimento econômico um desejo que a maioria das sociedades atuais aspiram para alcançar o seu desenvolvimento econômico, e não há dúvidas de que é uma condição essencial para atingir esse objetivo. No entanto, a partir da crise da década de 1980 e do surgimento da questão ecológica, explicitando custos não contabilizados dos processos produtivos, aprofundou-se uma visão crítica à idéia de que o crescimento econômico seria condição suficiente para o desenvolvimento econômico, percebendo-se que o crescimento econômico por si só podia ser extremamente excludente.

Como alternativa tem-se buscado um processo de desenvolvimento que tenha como base um crescimento econômico qualitativamente distinto e que possibilite a manutenção ou aumento, ao longo do tempo, do conjunto de bens econômicos, ecológicos e socioculturais, sem o que o desenvolvimento econômico não é sustentável, ou seja, é necessário aliar, de forma interdependente ao crescimento econômico, justiça social e conservação dos recursos naturais. Considera-se que o estabelecimento dessa interdependência favorece a igualdade de oportunidades, possibilitando um

7 A sociedade é concebida como unidades econômicas que seguem processos mecanicistas, cujas leis podem ser conhecidas cientificamente. A essa idéia se agrega a noção de evolução, como transformação gradual e constante, pela qual o progresso de uma nação ganha um caráter quase natural. O conceito de progresso, essencial para se entender os modelos clássicos de desenvolvimento, tem como base a crença na razão, no conhecimento técnico-científico como instrumento essencial para se conhecer a natureza e colocá-la a serviço do homem. (Diegues, 1992). 
aumento do número de pessoas com uma maior formação intelectual, e a conseqüente maximização do crescimento econômico.

O desenvolvimento sustentável tem como eixo central a melhoria da qualidade de vida humana dentro dos limites da capacidade de suporte dos ecossistemas e, na sua consecução, as pessoas, ao mesmo tempo que são beneficiários, são instrumentos do processo, sendo seu envolvimento fundamental para o alcance do sucesso desejado. Isto se verifica especialmente no que se refere à questão ambiental, na medida em que as populações mais pobres, ao mesmo tempo que são as mais atingidas pela degradação ambiental, em razão do desprovimento de recursos e da falta de informação, são também agentes da degradação.

Assim, de acordo com o conceito de desenvolvimento sustentável, para que o mesmo seja implementado é necessário visar à harmonia e à racionalidade, não somente entre o homem e a natureza, mas principalmente entre os seres humanos. As pessoas devem ser sujeito no processo de desenvolvimento, o qual deve ser visto não como fim em si mesmo, mas como meio de se obter, respeitando-se as características étnico-culturais, melhoria de qualidade de vida para diferentes populações, especialmente as mais pobres. Para tanto, as ações desenvolvimentistas devem priorizar investimentos e programas que tenham como lastro tecnologias e projetos comunitários que procurem sempre despertar a solidariedade e a mobilização por objetivos comuns nos grupos envolvidos.

Isso deve ser buscado considerando que o padrão de bem-estar estabelecido pela sociedade ocidental não é o único. Há uma grande diversidade ecológica e cultural entre os povos, apesar de historicamente sempre ter sido a meta do capitalismo, assim como também o foi do socialismo real, a homogeneização sociocultural como forma de favorecer a eficiência econômica. É necessário, para a sustentabilidade do desenvolvimento econômico, o resgate histórico-cultural das formas de relacionamento dos seres humanos entre si e com o meio ambiente nas diferentes sociedades como forma de definir o padrão de bem-estar adequado a estas.

Por outro lado, com o encolhimento virtual do globo, a primeira idéia que surge é a de uniformização, ou de que, em outras palavras, o processo de globalização se caracterize, em grande medida, pela padronização da produção, que, no caso da agricultura, como afirma Silva (1998), se estende em direção ao consumo.

Porém, como analisa Assis (2003), essa uniformização ocorre a partir de determinantes locais, na medida em que os atores globais determinam suas estratégias de atuação global em razão de vantagens ou desvantagens locacionais. Em outras palavras, as decisões de alocação do capital global ocorrem por causa de diferenças entre locais, ou seja, a busca é por homogeneização, mas as decisões capitalistas são motivadas por características locais.

Assim, quando se verifica a questão ambiental, percebe-se que apesar dos efeitos, na natureza, da utilização econômica apresentarem-se de forma cada vez mais global, as causas dos problemas ambientais têm, na maioria das vezes, a sua formação em condicionantes locais, determinando que as iniciativas de controle que se pretendam eficientes tenham seu início exatamente pela busca de formas de remover essas condicionantes.

Por outro lado, um processo coordenado de autodescobrimento das diferentes localidades de uma nação, que leve a investimentos em infra-estrututuras que favoreçam o desenvolvimento humano local, podem tornar-se ao mesmo tempo um atrativo aos fluxos internacionais de fatores. Efeito semelhante pode ser determinado com acordos de integração regional, onde ao mesmo tempo que se busca facilitar o acesso mútuo aos mercados internos, criam-se anteparos comuns contra a concorrência dos atores globais, como forma de permitir ganhos de economia de escala e vantagens 
comparativas intrabloco. No caso desses ganhos serem relevantes, é possível que o regionalismo estimule os investimentos globais, porém agora em outras bases. (Assis, 2003).

\section{Políticas PÚblicas PaRa O DESENVOLVIMENTO RURAl SUSTENTÁVEL}

Entende-se que o poder público só terá ação incentivadora eficaz caso venha a se apoiar em uma análise completa da situação. (Meynard e Girardin, 1994). Posto isto, e considerando-se as questões levantadas anteriormente sobre a função desempenhada pelo Estado num processo de difusão ampliada da agroecologia, percebe-se a importância do planejamento de estratégias e políticas públicas que permitam implementar uma proposta de desenvolvimento rural sustentável.

Em primeiro lugar, isso requer uma mudança de foco nas estratégias de desenvolvimento rural, historicamente utilizadas no Brasil, onde, conforme afirma Ehlers (1996), a exemplo de outros países em desenvolvimento, as propriedades patronais foram consideradas mais adequadas para a implantação do padrão convencional, tendo a agricultura familiar sido relegada a segundo plano, principalmente no que se refere a incentivos e acesso a crédito.

Em segundo lugar, a utilização do conceito de sustentabilidade exige uma reflexão sobre a possibilidade de se instituir políticas públicas para alcançar um desenvolvimento rural de caráter sustentável.

Isto leva a pensar nos contextos econômico-sociais nos quais essas políticas devem ser inseridas, de modo que a aplicação dessas políticas não seja feita de forma abstrata, desconsiderando-se os contextos históricos e culturais ${ }^{8}$ nos quais devam ser implementadas. Ao contrário, devem responder às necessidades naturais e sociais de tais contextos.

O que se está propondo é que para a implementação de formas de desenvolvimento rural sustentável deve ser construída uma lógica econômica e social que possibilite o desenvolvimento de múltiplas formas de agricultura, ou seja, em contraposição à lógica vigente, que dificulta caminhar nessa direção ao vincular-se à agricultura patronal em detrimento de outras formas de organização social da produção agrícola, como a agricultura familiar, fundamentais na reprodução de conhecimentos e modos de vida tradicionais. Deve-se considerar, inclusive, que a possibilidade de reprodução dessas diversas formas de organização social da produção agrícola é um bom indicador econômico-social de sustentabilidade.

Diversos autores (Barbieri, 1997; Buarque, 1991; Daly, 1996, 1993 e 1984; Sachs, 2000, 1993, 1986a e 1986b) já concluíram sobre a necessidade da humanidade definir seu limite de produção e consumo. É neste sentido que se ressalta a necessidade de uma nova ordem de organização social cujo centro de decisões não seja ditado pelo poder econômico, mas que outros segmentos possam exercer, de fato, controle social sobre seu futuro.

Sachs (1986a) apresenta os princípios do ecodesenvolvimento, termo que é fruto da Conferência de Estocolmo, realizada em 1972, como devendo ser a base de qualquer projeto, assinalando a necessidade de se evitar o crescimento imitativo. Argumenta, ademais, que as soluções devem ser encontradas localmente ou adaptadas às realidades locais. A imitação pura e simples tem provocado desigualdades sociais e degradação ambiental.

8 "As descontinuidades entre o presente e o passado não são apenas frutos de rupturas criativas; mas comumente refletem a prevalência da lógica da acumulação sobre a coerência do sistema de cultura. (...) Quando nos referimos à nossa identidade cultural, o que temos em conta é a coerência de nosso sistema de valores, do duplo ponto de vista sincrônico e diacrônico. Esse é o círculo maior que deve abarcar a política de desenvolvimento, tanto econômica como social. Somente uma clara percepção da identidade pode instilar sentido e direção a nosso esforço permanente de renovação do presente e construção do futuro.” (Furtado, 1998, p.71-72). 
As políticas devem ser construídas a partir da articulação das decisões locais e das demandas sociais. Assim, para o caso brasileiro são necessárias políticas que propiciem o incremento e distribuição da renda e dos meios de produção a contingentes maiores da população que carecem de inclusão social no cenário atual.

\subsection{Alternativas de política agrícola}

Historicamente, o processo de desenvolvimento excludente ocorrido no País se deu ancorado na possibilidade de expansão da fronteira agrícola (Furtado, 1963 e 1975), ${ }^{9}$ via de regra apoiada na agricultura patronal. Hoje, na medida em que aqui se propõe o estabelecimento de um processo de desenvolvimento rural baseado na agricultura familiar, entende-se que o acesso a terra é o pressuposto básico de qualquer política neste sentido. Assim, entende-se a reforma agrária como uma política fundamental para o desenvolvimento rural sustentável no Brasil, possibilitando a inclusão de pessoas que viviam à margem da sociedade e reanimando economias locais. (Guanziroli et al., 2001; Romeiro, 1994; Veiga, 2000).

No que se refere ao crédito agrícola, apesar de atualmente já existir, em nível federal, desde 1999, uma linha de financiamento agrícola específica para a agricultura orgânica, esta se destina somente ao custeio de produtores orgânicos já certificados, estando, na prática, restrita a agricultores orgânicos de maior nível de informação e organização. Porém, para que este instrumento de política agrícola cumpra efetivamente seu papel fundamental na difusão da agroecologia, é necessário que este crédito de custeio esteja vinculado à utilização de práticas agroecológicas, servindo de estímulo a que um número maior de agricultores orgânicos certificados não se restrinja a uma prática de produção orgânica em que o mote seja apenas a substituição de insumos convencionais por orgânicos.

Considera-se a substituição de insumos convencionais por orgânicos uma etapa importante no processo de transição de uma produção convencional para uma produção agroecológica, mas não pode ser considerada como etapa final nessa transição, que deve visar à garantia da sustentabilidade do sistema agrícola em suas dimensões econômicas, sociais, ecológicas e agronômicas. ${ }^{10}$

De forma complementar, além desse crédito de custeio requer-se ainda recursos para investimentos que viabilizem a conversão para a agricultura orgânica, com bases agroecológicas, de um número ampliado de produtores, financiando os custos desse processo de mudança.

Além disso, faz-se necessário o estabelecimento de mecanismos de crédito (custeio e investimento), associados à assistência técnica habilitada em agroecologia e à viabilização de canais de comercialização para uma produção agrícola diversificada (principalmente via mercado local), voltados a atender, num processo de desenvolvimento rural sustentável, às demandas de agricultores familiares descapitalizados, com baixo nível de informação, principalmente no caso de simples produtores de mercadorias ou semi-assalariados com frágil inserção no mercado ou produtores de subsistência.

Quanto às questões relativas à pesquisa e extensão rural, não podem ser esperados resultados a curto prazo, na medida em que as mudanças não devem ocorrer somente em nível institucional, pois a atuação, neste caso, deve ocorrer não só visando ao estabelecimento de linhas de trabalho que priorizem a mudança do paradigma tecnológico atualmente em voga na agricultura brasileira, de um enfoque agroquímico para um enfoque agroecológico, mas acima de tudo deve-se trabalhar

\footnotetext{
9 "O traço mais fundamental da economia agrícola brasileira é que nela coexiste o latifúndio com a abundância de terras. (...) Desta forma, não foi a escassez de terra, como na Europa, ou de mão-de-obra, como nos Estados Unidos, o que condicionou a evolução da estrutura agrária, e sim a escassez de capital e de capacidade empresarial." (Furtado, 1963, p. 259-260).

10 Para mais detalhes dessa discussão, ver Feiden et al. (2002).
} 
em busca de uma mudança de atitudes dos técnicos envolvidos em pesquisa e extensão rural nas instituições públicas.

Passo importante para esta mudança deve ser o estabelecimento das diversas experiências práticas de produção agroecológica de sucesso, aliado ao de ONGs com atuação na área de fomento de práticas agroecológicas, como referências que possibilitem a disseminação gradual, entre os técnicos das instituições públicas de pesquisa e extensão rural, da idéia de viabilidade da agroecologia como instrumento para viabilizar programa de desenvolvimento rural sustentável, especialmente entre pequenos agricultores familiares.

\subsection{Alternativas de política ambiental}

Para Rattner (1992), a construção de um processo de desenvolvimento que seja efetivamente sustentável, via simples retomada do crescimento econômico convencional combinado com medidas de proteção ou conservação do meio ambiente (contabilização de custos ambientais, cobrança de custos de restauração etc.), representa uma auto-ilusão ou mistificação.

Segundo Almeida et al. (2001), são poucos os países que podem apresentar planos e processos que permitam integrar suas políticas agrícolas e ambientais dentro do marco geral do desenvolvimento sustentável, acrescentando que as políticas são basicamente orientadas para a mitigação dos efeitos mais nocivos da agricultura convencional.

O estabelecimento de uma política ambiental, focada na agroecologia como ferramenta a auxiliar na implementação de processo de desenvolvimento agrícola sustentável, pode ocorrer por meio de dois tipos de instrumentos. O primeiro é conhecido como incentivo ou instrumento econômico, e se caracteriza por mecanismos de mercado que afetam o cálculo de custos e benefícios do agente econômico em relação ao meio ambiente, influenciando suas decisões. O segundo tipo é composto por mecanismos de regulação direta, também conhecidos como políticas de comando e controle, na medida em que determinam uma intervenção direta sobre a ação ambiental dos agentes econômicos.

Nesse caso, os agentes econômicos que degradam o meio ambiente são tratados legalmente como "ecodeliqüentes", não lhes sendo dada chance de escolha. (Almeida, 1997). Existe um padrão ambiental que deve ser seguido, caso contrário, aplicam-se as penalidades previstas, sendo a multa a mais usual. São estabelecidas, então, políticas de comando e controle que impõem, via diferentes instrumentos, modificações no comportamento dos agentes.

Os instrumentos econômicos, sob inspiração neoclássica, visam estabelecer uma melhoria da qualidade ambiental por meio de uma lógica em que o poder de escolha se mantém com os responsáveis pelo dano ambiental. Logo, os mesmos procuram internalizar os custos ambientais nas atividades econômicas, como forma de influenciar os agentes responsáveis pelo dano ambiental a modificarem o padrão de uso dos recursos ambientais. Estes instrumentos podem ser de dois tipos: os que geram gastos para o agente regulador (Estado), ou que geram recursos para este. O primeiro tipo é constituído por subsídios na forma de subvenções, incentivos fiscais ou empréstimos subsidiados concedidos com o intuito de incentivar os agentes econômicos a adotarem o padrão ambiental fixado, enquanto que o segundo aparece na forma de taxas e tarifas ou via comercialização de licenças de poluição, e representam, na prática, o estabelecimento de um "preço" pela poluição.

Tendo como referência os mecanismos de regulação direta, Assis e Arezzo (1997) propõem o uso da cobrança do custo ambiental dos insumos agrícolas industrializados como ferramenta de política que vise estimular a adoção, pelos agricultores, de práticas inerentes a sistemas orgânicos de produção. 
Considera-se essa uma idéia interessante na medida em que sua implementação favorece, indiretamente, a difusão de práticas agroecológicas ao restringir o uso de agroquímicos. Isto ocorre desde o momento que estes, ao internalizarem o custo ambiental de sua produção em seu preço final, têm reduzido o acesso de muitos agricultores a estes insumos, em especial os menos capitalizados, com destaque para os familiares, objetivo maior da política aqui proposta.

Mecanismos desse tipo são importantes a partir do momento que, em razão das características extremamente difusas das atividades agrícolas, se sabe, de antemão, das dificuldades existentes para que o poder público tenha um efetivo comando e controle de proibições, ou restrições, da atividade agrícola.

No entanto, para um maior favorecimento à implementação do processo de desenvolvimento em questão, torna-se necessário aliar ao mecanismo de regulação comentado instrumentos econômicos na forma de subsídios (subvenções e/ou incentivos fiscais) que incentivem os produtores a adotar o padrão de produção desejado.

Considera-se ainda que, para uma difusão ampliada de sistemas agroecológicos de produção, com base em mecanismos de política pública, é preciso, mais que tudo, influir no comportamento social, econômico e político da sociedade. Trata-se de perceber não a presença humana como causa dos problemas ambientais da agricultura, mas sim sua atividade inadequada que, como tal, deve ser coibida, ou seja, modificada na sua forma de usar os recursos naturais, que significa manejar os efeitos das atividades humanas por seu grau de intensidade e de extensão. Isto, porém, deve ser feito com a participação ativa da comunidade local, que deve ser informada sobre formas alternativas de coexistência racional entre o homem e o ambiente, ao mesmo tempo que deve ter seus valores culturais respeitados.

\section{DESENVOLVIMENTO RURAL SUSTENTÁVEL A PARTIR DE UMA AÇÃo LOCAL}

Considera-se que a adoção de um projeto político nacional coordenado, fundamentado na disseminação de experiências de desenvolvimento baseadas no desenvolvimento humano e nas potencialidades locais, que visem tirar da exclusão social a população marginalizada, incorporando-as ao processo produtivo, é um caminho possível para alcançar o desenvolvimento sustentável.

O desenvolvimento rural sustentável deve ser implementado em base local e regional porque é nessas instâncias que se pode contrapor alguma espécie de controle social legitimamente instituído à capacidade de influência do grande capital. E mais ainda: é necessário também que estas formas de controle social estejam articuladas entre si, de modo a garantir que essas bases locais nas quais se desenvolveram preservem sua autonomia, mantendo-se a salvo do domínio do capital ou do poder instituído. Com o agravante nos países subdesenvolvidos, em especial, de que o fortalecimento do poder local, quando não precedido de uma participação efetiva e democrática das comunidades envolvidas, tende a revigorar o poder conservador das classes dominantes locais.

É necessário, portanto, uma ação de pensar e agir localmente, de forma articulada entre os diferentes atores sociais, pois, como afirma Moreno (1997), um problema ambiental somente pode ser gerido socialmente se os agentes da sociedade (comunidade científica, meios de comunicação, associações de ecologistas etc.) o perceberem, o formularem, o observarem, o definirem, em outras palavras, o comunicarem. Portanto, a conversão de um problema ambiental em social depende mais da capacidade de observação da sociedade do que da magnitude objetiva da ameaça ambiental.

Assim, considerando que a ação local talvez seja o principal espaço que surge na chamada "era da globalização”, esta não pode se dar de forma descoordenada, sob pena de permitir o estabeleci- 
mento da trilha natural e histórica da acumulação capitalista de aumento crescente de desigualdade e exclusão social, e de que, mais do que antes, a "sustentabilidade" do desenvolvimento dos países do chamado Primeiro Mundo se deva ao subdesenvolvimento em outras áreas. É preciso, portanto, a adoção de um projeto político nacional coordenado, baseado na disseminação de experiências fundamentadas no desenvolvimento humano e nas potencialidades locais, que visem tirar da exclusão social a população marginalizada, incorporando-a ao processo produtivo.

A agroecologia, na medida em que possui como premissa básica uma produção agrícola que não agrida o meio ambiente, resgata a lógica da complexidade presente nas sociedades camponesas tradicionais, integrando propostas agroecológicas com outras voltadas ao desenvolvimento da agricultura familiar, a qual, em função da escala, favorece a conciliação entre a complexidade desejada e a supervisão e controle do processo de trabalho necessários.

Essa integração reforça a proposta de ação local como alternativa para o desenvolvimento sustentável, pois, tendo em vista que os agricultores familiares possuem um envolvimento local, viabilizam-se os mercados locais a partir de uma aproximação e orquestramento de interesses entre produtores, comerciantes e consumidores locais.

Isso é relevante na medida em que o processo de adoção de sistemas agroecológicos de produção não pode ser considerado como dependente exclusivamente da decisão do agricultor, devendo ser levado em consideração o contexto sócio-político em que o processo ocorre. Assim, a aproximação entre produtores, comerciantes e consumidores locais, ao revelar interesses comuns, amplia o espectro de pessoas envolvidas e comprometidas com a proposta de desenvolvimento sustentável anteriormente comentada.

\section{CONSIDERAÇÕES FINAIS}

A implementação de sistemas agrícolas sustentáveis depende de mudanças profundas do paradigma de desenvolvimento vigente na sociedade contemporânea, ou seja, entre outros aspectos, na elaboração de estratégias de desenvolvimento fundamentadas nos eixos local e regional,

$\mathrm{Na}$ agricultura, a valorização da dimensão local, aliada à aplicação dos princípios agroecológicos, garante a manutenção de variedades e cultivos locais - que são, via de regra, eliminados com as práticas agrícolas convencionais -, aumentando a agrobiodiversidade e reduzindo potencialmente os efeitos negativos do contato entre os remanescentes florestais e as matrizes agrícolas. Permite, ainda, o resgate dos conhecimentos locais das práticas tradicionais de manejo, valorizando e revitalizando as etnociências existentes.

Sistemas de produção agroecológicos, ao integrarem princípios ecológicos, agronômicos e socioeconômicos, surgem como possibilidade concreta de implementação de um processo democrático de desenvolvimento rural sustentável a partir de uma ação local, no qual os agricultores tenham condições de assumir a posição de atores principais.

Essa proposta depende, porém, fundamentalmente, de decisões políticas que procurem internalizar, no sistema econômico, os danos à natureza provocados pela atividade humana inadequada, ao mesmo tempo que, por meio do uso de instrumentos de política agrícola e ambiental, seja estimulada a adoção, pelos agricultores, de modelos agroecológicos de produção, com destaque para os que utilizam estrutura de trabalho familiar.

Em suma, entende-se que esse encaminhamento somente será possível com uma firmeza de propósitos da ação do poder público (duradoura e integrada em seus diferentes níveis), associada ao 
envolvimento efetivo da sociedade na construção de soluções, especialmente em nível local, para os problemas ambientais provocados pela agricultura convencional.

\section{REFERÊNCIAS BIBLIOGRÁFICAS}

Almeida, D. L. de. Sistema integrado de produção agroecológica - Fazendinha Agroecológica km 47. In: Souza, J. L. de; Carmo, C. A. S. (eds.). Encontro Nacional sobre Produção Orgânica de Hortaliças, 1, Vitória, 1998. Anais... Vitória: Empresa Capixaba de Pesquisa Agropecuária (EMCAPA), 1998. p. 77-94. (EMCAPA. Documentos 96).

Almeida, L. T. de. O debate internacional sobre instrumentos de política ambiental e questões para o Brasil. In: Anais... do $2^{\circ}$ Encontro da Sociedade Brasileira de Economia Ecológica (Eco-Eco), São Paulo, 1997, p. 3-21.

Almeida, S. G. de; Petersen, P.; Cordeiro, A. Crise socioambiental e conversão ecológica da agricultura brasileira. Rio de Janeiro: AS-PTA, 2001. 122p.

Assis, R. L. de. Agroecologia no Brasil: análise do processo de difusão e perspectivas. 2002. 150 p. Tese (Doutorado em Economia Aplicada), Universidade Estadual de Campinas, Campinas.

. Globalização, desenvolvimento sustentável, e ação local: o caso da agricultura orgânica. Cadernos de Ciência \& Tecnologia, Brasília, v. 20, n. 1, 2003 (no prelo).

. Diagnóstico da agricultura orgânica no Estado do Rio de Janeiro e propostas para sua difusão. 1993. $154 \bar{f}$. Dissertação (Mestrado), Universidade Federal Rural do Rio de Janeiro, Itaguaí.

Assis, R. L. de; Arezzo, D. C. de. Propostas de difusão da agricultura orgânica. Cadernos de Ciência \& Tecnologia, Brasília, v. 14, n. 2, p. 287-297, 1997.

Barbieri, J. C. Desenvolvimento e meio ambiente: as estratégias de mudanças da Agenda 21. Petrópolis: Vozes, 1997. 156p.

Boserup, E. Evolução agrária e pressão demográfica. São Paulo: Editora Hucitec, 1987. 141p.

Buarque, C. A desordem do progresso: o fim da era dos economistas e a construção do futuro. São Paulo: Paz e Terra, 1991. 186p.

Carmo, M. S. do; Comitre, V.; Dulley, R. D. Balanço energético de sistemas de produção na agricultura alternativa. Agricultura em São Paulo, São Paulo, v. 35, n. 1, p. 87-97, 1988.

Carmo, M. S. do; Magalhães, M. M. Agricultura sustentável: avaliação da eficiência técnica e econômica de atividades agropecuárias selecionadas no sistema não convencional de produção. Informações Econômicas, São Paulo, v. 29, n. 7, p. 7-98, 1999.

Costa, M. B. B. da. Agricultura moderna e sua crítica; Uma saída em relação as vertentes da agricultura alternativa. In: Seminário de Pesquisa em Agricultura Alternativa, Londrina, 1984. Anais... Londrina: Fundação Instituto Agronômico do Paraná (IAPAR), 1987. p. 68-91.

Daly, H. Beyond growth: the economics of sustainable development. Boston: Beacon Press, 1996. 254p.

. Para el bien común: reorientando la economía hacia la comunidad, el ambiente y un futuro sostenible. México: Fondo de Cultura Económica, 1993. 467p. . A economia do século XXI. Porto alegre: Mercado Aberto, 1984. 120p.

Darolt, M. R. As dimensões da sustentabilidade: um estudo da agricultura orgânica na região metropolitana de Curitiba, Paraná. 2000. 310p. Tese (Doutorado), Universidade Federal do Paraná (UFPR): Université Paris 7.

. Agricultura orgânica: a região metropolitana de Curitiba em destaque. Agricultura Biodinâmica, Botucatu, v. 82, p. 42-48, 1999. 
Diegues, A. C. S. Desenvolvimento sustentável ou sociedades sustentáveis. São Paulo em Perspectiva, São Paulo, v. 6, n. 1-2, p. 22-29, 1992.

Ehlers, E. Agricultura sustentável: origens e perspectivas de um novo paradigma. São Paulo: Livros da Terra, 1996. 178p.

Feiden, A.; Almeida, D. L. de; Vitoi, V.; Assis, R. L. de. Processo de conversão de sistemas de produção convencionais para sistemas de produção orgânicos. Cadernos de Ciência e Tecnologia, Brasília, v. 19, n. 2, p. 179-204, 2002.

Furtado, C. O capitalismo global. São Paulo: Paz e Terra, 1998. 84p.

. Análise do "modelo" brasileiro. Rio de Janeiro: Civilização Brasileira, 1975. 122p. (Coleção Perspectivas do Homem, 92 - Série Economia).

. Desenvolvimento e subdesenvolvimento. Rio de Janeiro: Fundo de Cultura, 1963. 270p.

Gliessman, S. R. Agroecologia - processos ecológicos em agricultura sustentável. Porto Alegre: Editora da Universidade Federal do Rio Grande do Sul, 2000. 653p.

Guanziroli, C. E.; Romeiro, A. R.; Buainain, A. M.; Di Sabbato, A.; Bittencourt, G. A. Agricultura familiar e reforma agrária no século XXI. Rio de Janeiro: Garamond, 2001.288p.

Hecht, S. B. A evolução do pensamento agroecológico. In: Altieri, M. (ed.), Agroecologia - as bases científicas da agricultura alternativa. Rio de Janeiro: PTA-FASE, 1989. p. 25-41.

Jesus, E. L. de. Da agricultura alternativa à agroecologia: para além das disputas conceituais. Agricultura sustentável, Jaguariúna, v. 1-2, p. 13-27, 1996.

. Histórico e filosofia da agricultura alternativa. Proposta, Rio de Janeiro, v. 27, p. 34-40, 1985.

Meynard, J.-M.; Girardin, Ph. Produzir de outro modo. Estudos Econômicos, São Paulo, v. 24, n. especial, p. 199-229, 1994.

Moreno, J. L. S. Principios filosóficos de la gestión ambiental. In: Ballesteros, J.; Adán, J. P. (eds.), Sociedad y medio ambiente. Madrid: Editorial Trota, 1997. p. 323-336.

Nascimento Jr., D. Agricultura orgânica no Estado de São Paulo. Agricultura Sustentável, Jaguariúna, v. 2, n. 2, p. 62-66, 1995.

Ndiaye, A.; Baêta, L. M.; Assis, R. L. de; Feiden, A. Análise da viabilidade econômica de produção de olerícolas em sistemas agroecológicos de produção. Agricultura Biodinâmica, Botucatu, v. 82, p. 33-37, 1999.

Payés, M. A. M. Sistemas de produção predominantes na região de Irati-Paraná; Um estudo de tipologia e diferenciação de produtores rurais. Londrina: Fundação Instituto Agronômico do Paraná (IAPAR), 1993. 86p. (IAPAR. Boletim Técnico, 41).

Rattner, H. Meio ambiente e desenvolvimento sustentável. São Paulo em Perspectiva, São Paulo, v. 6, n. 1-2, p. 30-33, 1992.

Romeiro, A. R. Meio ambiente e dinâmica de inovações na agricultura. São Paulo: Annablume: FAPESP, 1998. 272p.

. Agricultura sustentável, tecnologia e desenvolvimento rural. Agricultura Sustentável. Jaguariúna, v. 3, n. 1/2, p. 34-42, 1996.

. Renda e emprego: a viabilidade e o sentido da reforma agrária. In: Romeiro, A. R.; Guanziroli, C. E.; Palmeira, M.; Leite, S. (eds.), Reforma agrária: produção, emprego e renda - o relatório da FAO em debate. Rio de Janeiro: Vozes: IBASE: FAO, 1994. p. 75-86.

Sachs, I. Caminhos para o desenvolvimento sustentável. Rio de Janeiro: Garomond, 2000. 96p.

. Estratégias de transição para o século XXI: desenvolvimento e meio ambiente. São Paulo: Studio Nobel/FUNDAP, 1993. 103p.

. Ecodesenvolvimento: crescer sem destruir. São Paulo: Vértice, 1986a. 207p.

. Espaços, tempos e estratégias de desenvolvimento. São Paulo: Vértice, 1986b. 224p. 
Silva, J. G. da. A globalização da agricultura. In: Silveira, M. A.; Vilela, S. L. de O. (eds.), Globalização e sustentabilidade da agricultura. Jaguariúna: EMBRAPA/CNPMA, 1998. p. 29-42.

Veiga, J. E. da. A face rural do desenvolvimento: natureza, território e agricultura. Porto Alegre: Editora da Universidade Federal do Rio Grande do Sul, 2000. 197p. (Série Estudos Rurais).

. Problemas da transição à agricultura sustentável. Estudos Econômicos, São Paulo, v. 24, n. especial, p. 9-29, 1994. $21 \overline{\mathrm{p}}$.

. O desenvolvimento agrícola - uma visão histórica. São Paulo: EDUSP: Editora Hucitec, 1991. 